\title{
Air Quality of Work, Residential, and Traffic Areas During the COVID-19 Lockdown with Insights to Improve Air Quality
}

\section{Badr H Alharbi}

King Abdulaziz City for Science And Technology

Hatem A Alhazmi

King Abdulaziz City for Science And Technology

\section{Zaid Aldhafeeri ( $\square$ zaldhafeeri@kacst.edu.sa )}

King Abdulaziz City for Science And Technology https://orcid.org/0000-0002-6960-9776

\section{Research Article}

Keywords: Air pollutants, COVID-19, Lockdown, Nitrogen oxides, Ozone, AQI, Air Quality, Riyadh.

Posted Date: October 1st, 2021

DOl: https://doi.org/10.21203/rs.3.rs-820096/v1

License: (c) (i) This work is licensed under a Creative Commons Attribution 4.0 International License. Read Full License

Version of Record: A version of this preprint was published at International Journal of Environmental Research and Public Health on January 10th, 2022. See the published version at https://doi.org/10.3390/ijerph19020727. 


\section{Abstract}

This study investigated the concentrations of air pollutants $\left(\mathrm{NO}, \mathrm{NO}_{2}, \mathrm{NO}_{\mathrm{x}}, \mathrm{SO}_{2}, \mathrm{CO}, \mathrm{O}_{3}, \mathrm{PM}_{10}\right.$, and $\mathrm{PM}_{2.5}$ ) at three sites with different traffic loads (work, residential, and traffic sites) before, during, and after the COVID-19 lockdown. The main objective of this study was to evaluate the effects and associated potential pollution control implications of the lockdown on the quality of ambient air at three selected sites in the urban area of Riyadh City. The average concentrations of $\mathrm{NO}, \mathrm{NO}_{2}, \mathrm{NO}_{\mathrm{x}}$, and $\mathrm{CO}$ decreased during the lockdown period by $73 \%, 44 \%, 53 \%$, and $32 \%$ at the work site, $222 \%, 85 \%, 100 \%$, and $60 \%$ at the residential site, and $133 \%, 60 \%, 101 \%$, and $103 \%$ at the traffic site relative to the pre-lockdown period, respectively. The average concentration of $\mathrm{O}_{3}$ increased by $6 \%$ at the work site, whereas the concentration of $\mathrm{SO}_{2}$ increased by $27 \%$ at the residential site and decreased by $6.5 \%$ at the work site. The changes in $\mathrm{PM}_{10}$ and $\mathrm{PM}_{2.5}$ varied and did not exhibit a clear pattern. The air quality index (AQI) results indicated that the contribution to "undesired" air quality by $\mathrm{O}_{3}$ was $35.29 \%$ of the lockdown period at the work site while contributions to undesired air quality by $\mathrm{PM}_{10}$ and $\mathrm{PM}_{2.5}$ were $75.6 \%$ and $100 \%$ at the work site, $94.5 \%$ and $100 \%$ at the residential site, and $96.7 \%$ and $100 \%$ at the traffic site, respectively. The findings of this study are useful for devising effective urban pollution abatement policies. Applying control measures comparable to the lockdown measures over one week will result in a decrease of approximately $19 \%$ and $15 \%$ in $\mathrm{CO}$ mean concentration and $25 \%$ and $18 \%$ in $\mathrm{NO}_{2}$ mean concentration at residential and traffic sites, respectively. Significant mitigation of urban air pollution could be accomplished through intermittent implementations of strict pollution control measures.

\section{Introduction}

In most of the world, including America, Europe, Oceania, Asia, and Africa, SARS-CoV-2 has continuously spread since December 31, 2019 (Johns Hopkins, 2020; WHO, 2020a). However, it was only on March 12, 2020, that the World Health Organization (WHO) characterized COVID-19 as a pandemic and it had affected most of the world by then (WHO, 2020b). The high transmissibility and associated mortality rate of the virus (Hu et al., 2020) resulted in countries opting for different measures to contain it. These included a ban on public events, temporary shutting of all primary to higher academic institutions, encouragement of social distancing, near-total lockdowns, closure of non-essential businesses, and considerable reduction in public modes of transport such as buses, trains, and air travel. Although day-today human life was severely affected by these measures, the effect on air quality was generally positive (Dantas et al., 2020a; Parker et al., 2020; Saadat et al., 2020; Siciliano et al., 2020; Tobias et al., 2020).

Saudi Arabia (KSA) reported its first COVID-19 case on March 2, 2020. Thereafter, various measures were implemented to contain the pandemic. Suspension of the Umrah pilgrimage on March 4 was the first of these steps. On March 8, all school and university activities were suspended. The third measure was implemented on March 9, with a suspension of all international flights. Subsequently, on March 23, a nationwide total lockdown from 07:00 to 18:00 (local time) was imposed by the Saudi government owing to the continuous increase in the number of COVID-19 cases and the non-availability of a treatment or 
vaccine and any other effective treatment worldwide. The subsequent measure was the limiting or rather stopping of movement between different regions of the country from March 25, resulting in a nationwide full lockdown on April 6. On May 28, except for Mecca, the movement between provinces was partially permitted, and the partial lifting of the lockdown began in all other cities, which included the opening of shopping malls. The subsequent relaxations were implemented on May 31, for which, except for the Great Mosque of Mecca, prayers were permitted in all other mosques, and restrictions on restaurants, cafés, parks, and domestic flights were eased. On June 21, the final lifting of the lockdown was implemented for all regions (MoH 2020). A total of 262,772 confirmed cases of COVID-19 and 2,672 deaths were registered in Saudi Arabia from March 2 to July 25, 2020. In the capital of Riyadh, where our study was conducted, a partial curfew was enforced on the evening of March 23, 2020, from 19:00 to 06:00 every day for 21 days. On March 26, this curfew was increased to 15:00 to 06:00, with very limited exceptions involving life and safety until April 14, 2020. A 24-h curfew and total lockdown were imposed in Riyadh and all cities and regions across KSA for a four-day period, which coincided with the Eid holidays from May 23 to May 27, 2020. The 24-h curfew was replaced with a 15:00-to-06:00 curfew until June 21, and a nationwide curfew was ended by the Saudi Arabian government. In addition, the restrictions on businesses were lifted after three months of lockdown.

Motor vehicles are a significant source of urban air pollution. Transportation activities and use of vehicle transit were significantly reduced owing to the lockdown imposed as a proper protective measure to control and reduce the spread of COVID-19; this decrease in traffic was expected to significantly affect air pollution and air quality. For instance, the effect of partial lockdowns on the air quality in Rio de Janeiro, Brazil, was examined by Dantas et al. (2020); concentrations of $\mathrm{NO}_{2}, \mathrm{CO}$, and $\mathrm{PM}_{2.5}$ decreased, while that of $\mathrm{O}_{3}$ increased. Sicard et al. (2020) quantified the effect of the lockdown on air pollution in Wuhan and four other European cities, focusing on $\mathrm{O}_{3}, \mathrm{PM}_{2.5}, \mathrm{PM}_{10}$, and $\mathrm{NO}_{\mathrm{x}}$, from 2017 to 2019 and the early months of 2020; a significant decrease was observed in $\mathrm{PM}_{2.5}$ and $\mathrm{NO}_{2}$ concentrations during the lockdown period, while $\mathrm{O}_{3}$ increased. The decrease in air pollutants reflected the decreased activities in road traffic and industrial and energy sectors. Concentrations of $\mathrm{O}_{3}$ were observed to be inversely proportional to those of $\mathrm{NO}_{2}$, with the former increasing as the latter decreased during lockdowns. Similar results have been reported in other countries. Sharma et al. (2020) studied air pollution concentrations in 22 cities across India from March 16 to April 14, 2020, and compared the results with those of previous years up to 2017 . They observed that the air pollution concentration varied by region and pollutant. However, overall, $\mathrm{PM}_{2.5}$ concentrations decreased in many regions that implemented lockdowns, while $\mathrm{O}_{3}$ concentrations increased. They concluded that air quality could be improved if regulatory authorities implemented stricter regulations (Sharma et al., 2020). Furthermore, Kanniah et al. (2020) investigated spatial and temporal variations in different air pollutants and the aerosol optical depth (AOD) over Southeast Asian (SEA) countries, including Japan, Malaysia, Brunei, Singapore, and the Philippines. They observed up to a 70\% decrease in AOD in the urban and industrial areas of Malaysia during the lockdown period (March to April 2020) compared with 2018 and 2019; however, in northern SEA countries, AOD values remained high even during the lockdown period owing to agricultural activities. 
This study evaluated the expected subsequent change in the concentrations of air pollutants due to the decrease in traffic activities. This study explored the extent of variation in the concentrations of air pollutants and the associated air quality change during the lockdown in three different traffic-influenced environments (a low-traffic work site, moderate-traffic residential site, and heavy-traffic highway site). This could provide useful insights into and a better understanding of implementing proper regulatory plans to control and improve ambient air quality in the three types of investigated environments.

\section{Materials And Methods}

\subsection{Study area and site description}

Riyadh City, the capital of Saudi Arabia, is the largest metropolitan area in the Arabian Peninsula, with an urban area of $1798 \mathrm{~km}^{2}$ inhabited by over 6.5 million people, most of whom depend on private means of transportation as well as taxi and car rental services for commuting. The air-pollution-monitoring sites in this study were selected to reflect the effects of the lockdown on work, residential, and traffic-influenced environments featuring low, moderate, and heavy levels of traffic emissions, respectively. Figure 1 shows a satellite image of Riyadh City and the air quality monitoring sites investigated in this study. The King Abdul Aziz City for Science and Technology (KACST) mobile air quality station was located on the premises of KACST, which is a low-traffic environment. Moreover, the Almoroj air quality station was located in a residential area with a moderate-traffic environment, whereas the air quality station of the King Fahad highway was located in a heavy-traffic environment. The air quality stations of the Almoroj and King Fahad highway are approximately $5 \mathrm{~km}$ away from the KACST mobile air quality station and approximately $2.5 \mathrm{~km}$ from each other.

\subsection{Air pollution measurement}

The concentrations of air pollutants, including nitric oxide (NO), nitrogen dioxide $\left(\mathrm{NO}_{2}\right)$, nitrogen oxides $\left(\mathrm{NO}_{x}\right)$, sulfur dioxide $\left(\mathrm{SO}_{2}\right)$, carbon monoxide $(\mathrm{CO})$, ozone $\left(\mathrm{O}_{3}\right)$, particulate matter equal to or less than 10 microns in diameter $\left(\mathrm{PM}_{10}\right)$, and particulate matter equal to or less than 2.5 microns in diameter $\left(\mathrm{PM}_{2.5}\right)$ were investigated in this study. The analysis provided in this paper is based on three measurement periods: April 2020 to June 2020 for the KACST mobile air quality station, and March 2020 to June 2020 and March 2019 to June 2019 for both air quality stations on the Almoroj and King Fahad highway. Over these study periods, continuous concentration measurements of seven air pollutants $\left(\mathrm{NO}, \mathrm{NO}_{2}, \mathrm{NO}_{\mathrm{x}}, \mathrm{SO}_{2}\right.$, $\mathrm{CO}, \mathrm{PM}_{10}$, and $\mathrm{PM}_{2.5}$ ) were obtained from air quality stations located in Almoroj and six air pollutants ( $\mathrm{NO}, \mathrm{NO}_{2}, \mathrm{NO}_{x}, \mathrm{CO}, \mathrm{PM}_{10}$, and $\mathrm{PM}_{2.5}$ ) from King Fahad highway areas. These two air quality stations are operated by the Royal Commission for Riyadh. For the KACST mobile air quality station, eight air pollutants $\left(\mathrm{O}_{3}, \mathrm{NO}, \mathrm{NO}_{2}, \mathrm{NO}_{x}, \mathrm{SO}_{2}, \mathrm{CO}, \mathrm{PM}_{10}\right.$, and $\left.\mathrm{PM}_{2.5}\right)$ were measured.

In both air quality stations of Almoroj (M-station) and King Fahad highway (F-station), air pollution was measured using Environment $\mathrm{SA}$ analyzers. $\mathrm{NO}$ and $\mathrm{NO}_{2}$ were measured based on the chemiluminescence technology, the standard method for measuring nitrogen oxides (EN 14211), using a 
nitrogen oxide analyzer (Environment SA AC 32M) with the lowest detectable limit of $<0.2 \mathrm{ppb} . \mathrm{O}_{3}$ was measured using an LED-based ultraviolet photometric $\mathrm{O}_{3}$ analyzer (Environment $\mathrm{SA} \mathrm{O}_{3} 42 \mathrm{M}$ ) with the lowest detectable limit of $0.2 \mathrm{ppb} . \mathrm{SO}_{2}$ was measured using ultraviolet fluorescence (UVF), the standard method of measuring $\mathrm{SO}_{2}$ (EN 14212), using an $\mathrm{SO}_{2}$ analyzer (Environment SA AF 22M) with the lowest detectable limit of $<0.4 \mathrm{ppb}$. CO was measured using a non-dispersive infrared (NDIR) CO analyzer (Environment SA CO 12M) with the lowest detectable limit of $0.05 \mathrm{ppm} . \mathrm{PM}_{10}$ and $\mathrm{PM}_{2.5}$ were measured using a suspended particulate monitor (Environment SA MP101M) with the lowest detectable limit of 0.5 $\mu \mathrm{g} / \mathrm{m}^{3}$ based on the standard ISO 10473 beta gauge measurement method for the continuous measurement of concentration of fine dust in ambient air.

In the KACST mobile air quality station (K-station), air pollution was measured using HORIBA analyzers. $\mathrm{NO}$ and $\mathrm{NO}_{2}$ were measured based on a combination of the dual cross-flow modulation-type chemiluminescence principle and referential calculation method using a nitrogen oxide analyzer (HORIBA APNA-370), with the lowest detectable limit of $0.5 \mathrm{ppb} . \mathrm{O}_{3}$ was measured based on the non-dispersive ultraviolet absorption method (NDUV) in conjunction with the comparative calculation method using an $\mathrm{O}_{3}$ analyzer (HORIBA APOA-370), with the lowest detectable limit of $0.5 \mathrm{ppb}$. $\mathrm{SO}_{2}$ was measured based on the UVF using an $\mathrm{SO}_{2}$ analyzer (HORIBA APSA-370), with the lowest detectable limit of $0.5 \mathrm{ppb}$. CO was measured using an NDIR CO analyzer (HORIBA APMA-370) with the lowest detectable limit of $0.02 \mathrm{ppm}$. Non-methane hydrocarbon (NMHC) concentrations were measured using flame ionization detection (FID) with a selective combustion analyzer (HORIBA APHA-370), with the lowest detectable limit of 0.022 ppmC. $\mathrm{PM}_{10}$ and $\mathrm{PM}_{2.5}$ were measured using a Grimm EDM 365 dust monitor (Grimm Aerosol Technik $\mathrm{GmbH}$, Ainring, Germany), with a resolution of $0.1 \mu \mathrm{g} / \mathrm{m}^{3}$.

\subsection{Degree of similarity}

The degree of similarity or discrepancy of the air pollutants among the three air quality stations was calculated using the following convergence-divergence ratio (CD) (Wongphatarakul et al., 1998):

$\mathrm{CD}_{j k}=\sqrt{\frac{1}{p} \sum_{i=1}^{p}\left(\frac{x i j-x i k}{x i j+x i k}\right)^{2}}$

Here, $x i j$ is the average concentration of pollutant $i$ at a certain air quality station, $j$ and $k$ are two air quality stations, and $p$ is the number of values representing each pollutant; three values (average, maximum, and minimum) were used to represent each pollutant. If the calculated CD tended towards zero, measurements from both air quality stations were considered to be similar, whereas if the CD was closer to one, measurements from the two air quality stations were considered to be different.

\subsection{Air quality index}

The air quality index (AQI) is a tool that assesses and describes the status of air quality and associated potential health implications. For evaluation and comparison, the AQIs for the three investigated sites 
were calculated according to the standard formulae of the United States Environmental Protection Agency (USEPA) and USEPA air quality standard limits. The measured concentrations of air pollutants were averaged to match the standard limits and classified according to the AQI breakpoints. In this study, the average times selected for $\mathrm{AQI}$ calculations for $\mathrm{PM}_{10}, \mathrm{PM}_{2.5}, \mathrm{O}_{3}, \mathrm{NO}_{2}, \mathrm{CO}$, and $\mathrm{SO}_{2}$ were 24, 24, 1 and $8,1,1$, and $1 \mathrm{~h}$, respectively, and the breakpoints for each selected pollutant were according to the USEPA (USEPA, 1999) indexing procedure (Table 1S). Typically, the scale of the AQI is divided into six general categories that are associated with health messages that convey the health implications of air quality and pollutant-specific health effects and sensitive groups. These categories are "Good," "Moderate," "Unhealthy for sensitive groups," "Unhealthy," "Very unhealthy," and "Hazardous." In this study, air quality with no observable health effects on the humans was considered good whereas air quality in the Moderate, Unhealthy for sensitive groups, Unhealthy, Very unhealthy, and Hazardous ranges that affect human health was considered as undesired.

\section{Results And Discussion}

\subsection{Evaluation and comparison of air pollutants concentrations}

A comparison of the air pollutant concentrations at the investigated sites and times indicated their differences among the residential, traffic, and work sites during the selected study periods. The CD method of comparison was applied to the concentrations of air pollutants, and the resultant values described the degree of similarity between the two sites. Similar sites had CD values approaching zero, whereas different sites had $C D$ values approaching one. Table $2 S$ shows the degree of similarity or discrepancy in the air pollutant concentrations among the selected residential, traffic, and work sites during the selected study periods. Generally, the highest dissimilarity was observed for $\mathrm{NO}_{x}$ with a $\mathrm{CD}$ value of 0.66 , followed by $\mathrm{CO}$ and $\mathrm{SO}_{2}$ with $\mathrm{CD}$ values of 0.61 and 0.60 , respectively. In contrast, low discrepancy or high similarity was observed for $\mathrm{PM}_{10}$ and $\mathrm{PM}_{2.5}$ concentrations during all investigated periods with $C D$ values ranging from as low as 0.04 and up to 0.34 (Table $2 S$ ).

In a pairwise comparison of the unrestricted periods, the highest dissimilarity between residential and traffic sites was indicated by a divergence value of 0.43 for NO, whereas the highest dissimilarity between residential and work sites was indicated by divergence value of 0.60 for $\mathrm{SO}_{2}$, and that between traffic and work sites was indicated by divergence value of 0.66 for $\mathrm{NO}_{\mathrm{x}}$ (Table 2S). In contrast, the least discrepancy, and thus the highest similarity, was observed between residential and work sites (divergence value of 0.12 ) for NO, followed by that between residential and traffic sites (divergence ratio of 0.17 ) for $\mathrm{NO}_{2}$ and that between residential and traffic sites (divergence value of 0.21 ) for $\mathrm{CO}$ (Table 2S). The discrepancy in $\mathrm{CO}$ and $\mathrm{NO}_{2}$ pollutants between traffic and work sites (divergence ratios of 0.56 and 0.57 , respectively) and between residential and work sites (divergence values of 0.40 and 0.56 , respectively) exceeded the discrepancy in $\mathrm{CO}$ and $\mathrm{NO}_{2}$ pollutants between residential and traffic sites (divergence 
values of 0.21 and 0.17 , respectively) (Table $2 \mathrm{~S}$ ). Therefore, in terms of $\mathrm{CO}$ and $\mathrm{NO}_{2}$ concentrations during the unrestricted periods, sites more similar and dissimilar to the residential site (M-station) were the traffic site (F-station) and work site (K-station), respectively.

In a pairwise comparison of the lockdown period, the highest dissimilarity between residential and traffic sites was indicated by a divergence value of 0.46 for NO, while the highest dissimilarity between residential and work sites was indicated by a divergence value of 0.57 for $\mathrm{SO}_{2}$, and that between traffic and work sites was indicated by a divergence value of 0.61 for $\mathrm{CO}$ (Table 2S). In contrast, the least discrepancy, and thus the highest similarity, was observed between the residential and work sites (divergence ratio of 0.04 ) for $\mathrm{PM}_{2.5}$, followed by that between the traffic and work sites (divergence value of 0.09 ) for $\mathrm{PM}_{2.5}$ and that between the residential and traffic sites (divergence value of 0.20 ) for $\mathrm{CO}$ (Table 2S). The discrepancy in $\mathrm{CO}$ and $\mathrm{NO}_{2}$ pollutants between the traffic and work sites (divergence values of 0.61 and 0.46 , respectively) and between the residential and work sites (divergence values of 0.50 and 0.53 , respectively) exceeded the discrepancy in $\mathrm{CO}$ and $\mathrm{NO}_{2}$ pollutants between the residential and traffic sites (divergence values of 0.20 and 0.33 , respectively) (Table $2 \mathrm{~S}$ ). Therefore, in terms of CO and $\mathrm{NO}_{2}$ concentrations during the lockdown period, sites more similar and dissimilar to the residential site (M-station) were the traffic site (F-station) and work site (K-station), respectively. Moreover, Table 2S also indicates that the lockdown decreased the range of $C D$ values describing the similarity and discrepancy degrees among the three sites in terms of $\mathrm{NO}_{1} \mathrm{NO}_{2}$, and $\mathrm{NO}_{x}$, while the lockdown increased the range of $\mathrm{CD}$ values in terms of $\mathrm{CO}$. The range of $\mathrm{CD}$ values in terms of $\mathrm{NO}, \mathrm{NO}_{2}$, and $\mathrm{NO}_{x}$ decreased by $185 \%$ (from $0.12-0.49$ to $0.36-0.49$ ), $100 \%$ (from $0.17-0.57$ to $0.33-0.53$ ), and $207 \%$ (from $0.23-0.66$ to $0.39-0.53$ ), respectively. In contrast, the range of $C D$ values in terms of $C O$ increased by $15 \%$ (from $0.21-$ 0.56 to $0.20-0.61)$.

To evaluate the effect of the lockdown on air quality, the measured concentrations of air pollutants for two of the three studied sites (residential M-station and traffic F-station) during the lockdown (denoted by M-20 and F-20 for the residential and traffic sites, respectively) were compared with those recorded during two selected periods. The first period of these was the corresponding period of the lockdown in 2019 (denoted by M-19 and F-19 for the residential and traffic sites, respectively) and the second period was the 22 days before the lockdown in 2020 (denoted by M-pre-20 and F-pre-20 for the residential and traffic sites, respectively). For the work site (K-station), the measured concentrations of air pollutants during the lockdown (K-20) were compared only with those measured during the 22 days after the lockdown in 2020 (K-post) because of the unavailability of recorded data in 2019 and pre-lockdown in 2020. Figure 2 depicts a boxplot comparison of the hourly concentrations of air pollutants, including $\mathrm{CO}, \mathrm{NO}, \mathrm{NO}_{2}, \mathrm{NO}_{\mathrm{x}}$, $\mathrm{SO}_{2}, \mathrm{O}_{3}$, and daily concentrations of particulate matter $\left(\mathrm{PM}_{2.5}\right.$ and $\left.\mathrm{PM}_{10}\right)$. Generally, the interquartile ranges of most investigated gaseous air pollutants were wider for the traffic site than for the residential and work sites. All sites experienced significant decreases in the concentration levels of gaseous air pollutants during the lockdown period, except for $\mathrm{SO}_{2}$ at the residential site and $\mathrm{O}_{3}$ at the work site, both of which increased (Figs. 2 and 3 ). An increase in $\mathrm{O}_{3}$ concentrations was observed during the lockdown in 
many countries around the world (Chen et al., 2020; Monserrate et al., 2020; Nie et al., 2020; Shi and Brasseur, 2020; Li et al., 2020). In the three studied sites, the lockdown period compared with other periods also had the lowest median and mean concentration values of the investigated gaseous air pollutants, except for $\mathrm{SO}_{2}$ in the residential site and $\mathrm{O}_{3}$ at the work site (Fig. 2). Moreover, the maximum outlier values of gaseous air pollutants were higher at traffic sites than at residential and work sites, but generally were approximately comparable for $\mathrm{PM}_{10}$ and $\mathrm{PM}_{2.5}$ at all three sites (Fig. 2). The $\mathrm{PM}_{10}$ and $\mathrm{PM}_{2.5}$ concentration changes were predominantly controlled by the frequent dust storms affecting the city; thus, the lockdown had only a slight effect on their concentration levels.

The percent changes in the concentrations of air pollutants at each station during the lockdown period are shown in Fig. 3. The greatest decrease during lockdown was observed in the NO concentrations at all three sites. The residential and traffic sites experienced the highest decrease in the concentration levels of $\mathrm{NO}, \mathrm{NO}_{x}$, and $\mathrm{NO}_{2}$, while the work site had the lowest decreases in concentration levels of air pollutants. Furthermore, the residential and work sites exhibited similar decreasing profiles $\left(\mathrm{NO} \otimes \mathrm{NO}_{\mathrm{x}} \otimes \mathrm{NO}_{2} \otimes \mathrm{CO}\right)$. Comparing pollutant concentrations of the lockdown period with those of the corresponding period in 2019 and to the pre-lockdown period in 2020, the traffic site had comparable decreases in concentration levels of gaseous air pollutants, while the residential site exhibited comparable decreases only in concentration levels of $\mathrm{NO}_{\mathrm{x}}$ and $\mathrm{NO}_{2}$. At this residential site, $\mathrm{NO}$ and $\mathrm{CO}$ had different decreases in concentration levels whereas $\mathrm{SO}_{2}$ increased in concentration during the lockdown period relative to the pre-lockdown period in 2020 but not with respect to the period in 2019 . This indicated that the residential site experienced specific activities in 2019 (presumably construction activities), resulting in higher ambient concentrations of $\mathrm{SO}_{2}$ than those recorded during the lockdown period. The observed increase in $\mathrm{SO}_{2}$ concentration at the residential site during the lockdown relative to those of the pre-lockdown period in 2020 might be due to increased activities of heavy-duty diesel engines associated with construction activities near the site. However, this increase in construction activities was less than that in 2019. However, comparing $\mathrm{PM}_{10}$ concentrations during the lockdown period with those during the corresponding period in 2019 at the traffic site revealed a decrease of $\sim 22 \%$ in $\mathrm{PM}_{10}$ concentrations during the lockdown, while the same comparison at the residential site increased by $~ 2 \%$ in $\mathrm{PM}_{10}$ concentrations during the lockdown. Assuming similar $\mathrm{PM}_{10}$ concentrations at the two sites resulting from dust storms affecting the city, this probably indicated that the residential site had additional emission sources of $\mathrm{PM}_{10}$ other than dust storms. In addition to this increase in $\mathrm{PM}_{10}$ at the residential site, no increases in pollutant concentrations were observed at the residential and traffic sites when the pollutant concentrations of the lockdown period were compared with those of the corresponding period in 2019. At the work site, the observed $\mathrm{O}_{3}$ concentration increase during the lockdown was due to the observed declining NOx concentration levels and evidence of a hydrocarbon-limited regime in Riyadh, as previously reported (Alharbi et al., 2017). In such a regime, the $\mathrm{O}_{3}$ production rate is limited by the supply of hydrocarbons, and $\mathrm{O}_{3}$ concentrations increase with increasing hydrocarbons and decrease with increasing $\mathrm{NO}_{\mathrm{x}}$ (Sillman et al. 1990; Sillman and He, 2002; Kleinman et al., 2005). 
Figure 4 shows the diurnal distribution of average hourly $\mathrm{O}_{3}$ and $\mathrm{NO}_{\mathrm{x}}$ concentrations and their correlations during and after the lockdown at the work site (K-station). A typical systematic pattern of diurnal $\mathrm{O}_{3}$ change is characterized by a daytime high and nighttime low. This pattern was observed only during the period after the lockdown ended. Both periods (during and after the lockdown) had typical daytime maxima. However, during the lockdown period, the minima were at daytime rather than nighttime (Figs. $4 \mathrm{a}$ and $4 \mathrm{~b}$ ). Following the diurnal variation in solar radiation, the $\mathrm{O}_{3}$ concentration increased gradually after sunrise and reached its highest concentration of $\sim 67 \mathrm{ppb}$ at 14:00 during the lockdown and $\sim 75 \mathrm{ppb}$ at 10:00-12:00 during the period after the lockdown and gradually declined thereafter (Figs. $4 \mathrm{a}$ and $4 \mathrm{~b}$ ). The $\mathrm{O}_{3}$ concentration decreased to its lowest value of $\sim 32 \mathrm{ppb}$ at 7:00 (after sunrise) during the lockdown and to $\sim 22 \mathrm{ppb}$ at 5:00 (before sunrise) during the period after the lockdown (Figs. $4 \mathrm{a}$ and $4 \mathrm{~b}$ ). Moreover, the nighttime $\mathrm{O}_{3}$ concentration during the lockdown period (ranging from 34.1 to $47.3 \mathrm{ppb}$ ) was higher than the nighttime $\mathrm{O}_{3}$ concentration during the period after the lockdown (ranging from 22.4 to $34.6 \mathrm{ppb}$ ). In addition, Figs. $4 \mathrm{c}$ and $4 \mathrm{~d}$ show the diurnal patterns of $\mathrm{NO}_{\mathrm{x}}$ corresponding to the same two periods. The anticorrelation between $\mathrm{O}_{3}$ and $\mathrm{NO}_{\mathrm{x}}\left(\mathrm{R}^{2}=0.59\right)$ during the period after the lockdown is clearly illustrated by comparing Figs. $4 \mathrm{~b}, 4 \mathrm{~d}$, and $4 \mathrm{f}$, whereas this anticorrelation did not exist $\left(\mathrm{R}^{2}=\sim 0\right.$ ) during the lockdown period (Figs. 4a, 4c, and 4e). Furthermore, these same figures show that the $\mathrm{NO}_{\mathrm{x}}$ concentration during the lockdown period lay in the range of 18.8$30.2 \mathrm{ppb}$ during daytime ( 6:00-19:00) and in the range of 17.6-24.5 ppb during nighttime. In contrast, the $\mathrm{NO}_{\mathrm{x}}$ concentration during the period after the lockdown lay in the range of $6.9-51 \mathrm{ppb}$ during the daytime and in the range of 27.3-57.7 ppb during nighttime. The reactions of $\mathrm{NO}$ with $\mathrm{O}_{3}\left(\mathrm{NO}+\mathrm{O}_{3} \rightarrow\right.$ $\left.\mathrm{NO}_{2}+\mathrm{O}_{2}\right)$ and $\mathrm{NO}_{2}$ with $\mathrm{O}_{3}\left(\mathrm{NO}_{2}+\mathrm{O}_{3} \rightarrow \mathrm{NO}_{3}+\mathrm{O}_{2}\right)$ control the nighttime $\mathrm{O}_{3}$ concentration (Jacobson, 2002; Seinfeld and Pandis, 1998). Therefore, the relatively lower nighttime $\mathrm{NO}_{x}$ concentration during the lockdown period compared with those during the period after the lockdown indicated lower $\mathrm{O}_{3}$ depletion by $\mathrm{NO}_{x}$ and explained the relatively higher nighttime $\mathrm{O}_{3}$ concentration during the lockdown period. Finally, the distribution of the hourly average $\mathrm{O}_{3}$ concentrations observed during the two periods is shown in Figs. $4 \mathrm{~g}$ and $4 \mathrm{~h}$. In these figures, hourly $\mathrm{O}_{3}$ concentrations are placed into predetermined $20 \mathrm{ppb}$ bins. A maximum frequency value at $\mathrm{O}_{3}$ concentrations of $40-60 \mathrm{ppb}$ was observed during both periods. However, $\mathrm{O}_{3}$ concentrations during the lockdown period followed a distribution that resembled a normal distribution to an extent, while those during the period after the lockdown exhibited a skewed distribution with a peak to the left (i.e., at low values) and a tail to the right (i.e., at high values). This type of skewed distribution indicated that anthropogenic pollution, particularly road traffic emissions, had a significant effect on the $\mathrm{O}_{3}$ concentrations observed during the period after the lockdown.

\subsection{Analysis of exceedances and air quality index for individual pollutants}

For evaluation and comparison, we calculated air pollutant exceedances and AQIs. At the three studied sites, the air pollutant exceedances during the lockdown period were calculated based on the General Authority for Meteorology and Environmental Protection (GAMEP) and USEPA standards (Table 3S). The 
AQIs in this study were calculated using the USEPA standard formulae and air quality standard limits, as stated in the Materials and Methods section. Air quality data covering the corresponding lockdown period in 2019, the pre-lockdown period in 2020, and the lockdown and post-lockdown periods were used to calculate the index values. $\mathrm{PM}_{10}$ and $\mathrm{PM}_{2.5}$ were averaged daily, and $\mathrm{O}_{3}$ was averaged every 1 and $8 \mathrm{~h}$ to match the breakpoint. The AQIs for individual pollutants during the selected periods are listed in Table 1. No hourly exceedances for $\mathrm{CO}, \mathrm{NO}_{2}$, and $\mathrm{SO}_{2}$, daily exceedances for $\mathrm{SO}_{2}$, and $8 \mathrm{~h}$ exceedances for $\mathrm{CO}$ were observed in all stations during the entire lockdown period (Table 2). Similarly, the AQI for $\mathrm{CO}$ and $\mathrm{SO}_{2}$ had $0 \%$ undesired air at all stations during the lockdown (Table 1). However, the AQI for hourly $\mathrm{NO}_{2}$ concentrations revealed $0.7 \%, 1.06 \%$, and $0.61 \%$ undesired air quality at the residential, traffic, and work sites, respectively, during the lockdown (Table 1 ). In contrast, the AQI for hourly $\mathrm{NO}_{2}$ concentrations had $6.99 \%$ undesired air quality during the corresponding lockdown period in 2019 and $4.39 \%$ undesired air quality during the pre-lockdown period in 2020 at the residential site. Similarly, the AQI for hourly $\mathrm{NO}_{2}$ concentrations had $6.99 \%$ undesired air quality during the corresponding lockdown period in 2019 and $3.74 \%$ undesired air quality during the pre-lockdown period in 2020 at the traffic site, while the AQI for hourly $\mathrm{NO}_{2}$ concentrations had $1.83 \%$ undesired air quality during the post-lockdown period at the work site. The percentages of undesired air quality reflected a good improvement in air quality in terms of $\mathrm{NO}_{2}$ at their respective sites during the lockdown since the other investigated periods (the corresponding lockdown period in 2019, pre-lockdown period in 2020, and post-lockdown period) experienced higher percentages of undesired air quality at these sites (Table 1).

Table 1. Percentage of undesirable air (moderate, unhealthy for sensitive groups, unhealthy, very unhealthy, and hazardous) as indicated by AQIs for individual pollutants during the correspondinglockdown period in 2019 , pre-lockdown period in 2020 , lockdown, and the post-lockdown periods.

\begin{tabular}{|c|c|c|c|c|c|c|c|}
\hline \multirow{3}{*}{ Station-Period } & \multicolumn{7}{|c|}{ Air Quality Index } \\
\hline & \multirow{2}{*}{$\begin{array}{c}\mathrm{CO} \\
1-\mathrm{h}\end{array}$} & \multirow{2}{*}{$\begin{array}{l}\mathrm{SO}_{2} \\
1-\mathrm{h}\end{array}$} & \multirow{2}{*}{$\begin{array}{l}\mathrm{NO}_{2} \\
1-\mathrm{h}\end{array}$} & \multicolumn{2}{|c|}{$\mathrm{O}_{3}$} & \multirow{2}{*}{$\begin{array}{l}\mathrm{PM}_{25} \\
24-\mathrm{b}\end{array}$} & \multirow{2}{*}{$\begin{array}{l}\mathrm{PM}_{10} \\
24-\mathrm{h}\end{array}$} \\
\hline & & & & $1-\mathrm{h}$ & 8-h & & \\
\hline \multirow{2}{*}{ M-19 } & $0 \%$ & $0.09 \%$ & $6.99 \%$ & \multirow{2}{*}{-} & \multirow{2}{*}{-} & $98.99 \%$ & $96.70 \%$ \\
\hline & Undesirable & Undesirable & Undesirable & & & Undesirable & Undesirable \\
\hline \multirow{2}{*}{ M-Pre 20} & $0 \%$ & $0 \%$ & $4.39 \%$ & \multirow{2}{*}{-} & \multirow{2}{*}{-} & $100 \%$ & $100 \%$ \\
\hline & Undesirable & Undesirable & Undesirable & & & Undes irable & Undesirable \\
\hline \multirow{2}{*}{$\mathrm{M}-20$} & $0 \%$ & $0 \%$ & $0.70 \%$ & \multirow{2}{*}{-} & \multirow{2}{*}{-} & $100 \%$ & $94.51 \%$ \\
\hline & Undesirable & Undesirable & Undesirable & & & Undesirable & Undesirable \\
\hline \multirow{2}{*}{ F-19 } & $0.05 \%$ & & $6.99 \%$ & \multirow{2}{*}{-} & \multirow{2}{*}{-} & $100 \%$ & $93.40 \%$ \\
\hline & Undesirable & & Undesirable & & & Undesirable & Undesirable \\
\hline \multirow{2}{*}{ F-Pre 20} & $0 \%$ & - & $3.74 \%$ & \multirow{2}{*}{-} & \multirow{2}{*}{-} & $95.50 \%$ & $95.50 \%$ \\
\hline & Undesirable & - & Undesirable & & & Undes irable & Undesirable \\
\hline \multirow{2}{*}{$\mathrm{F}-20$} & $0 \%$ & - & $1.06 \%$ & \multirow{2}{*}{-} & \multirow{2}{*}{ - } & $100 \%$ & $96.70 \%$ \\
\hline & Undesirable & - & Undesirable & & & Undesirable & Undesirable \\
\hline \multirow{2}{*}{$\mathrm{K}-20$} & $0 \%$ & $0 \%$ & $0.61 \%$ & $0.05 \%$ & $35.29 \%$ & $100 \%$ & $75.61 \%$ \\
\hline & Undesirable & Undesirable & Undesirable & Undesirable & Undesirable & Undesirable & Undesirable \\
\hline \multirow{2}{*}{ K-Post 20} & $0 \%$ & $0 \%$ & $1.83 \%$ & $0.38 \%$ & $32.56 \%$ & $100 \%$ & $100 \%$ \\
\hline & Undesirable & Undesirable & Undesirable & Undesirable & Undesirable & Undesirable & Undesirable \\
\hline
\end{tabular}


Table 2

Air pollutant exceedances in reference to GAMEP and USEPA standards during the lockdown period at the three studied sites (residential $(M)$, traffic $(F)$, and work $(K)$ ).

\begin{tabular}{|c|c|c|c|c|c|c|c|}
\hline \multirow{3}{*}{ Averaging Time } & \multirow{3}{*}{ Pollutant } & \multicolumn{6}{|c|}{ Exceedances } \\
\hline & & \multicolumn{2}{|c|}{ M-Station } & \multicolumn{2}{|c|}{ F-Station } & \multicolumn{2}{|c|}{ K-Station } \\
\hline & & GAMEP & USEPA & GAMEP & USEPA & GAMEP & USEPA \\
\hline \multirow[t]{4}{*}{$1 \mathrm{~h}$} & $\mathrm{NO}_{2}$ & 0 & 0 & 0 & 0 & 0 & 0 \\
\hline & $\mathrm{O}_{3}$ & - & - & - & - & 2 & 2 \\
\hline & $\mathrm{SO}_{2}$ & 0 & 0 & - & - & 0 & 0 \\
\hline & $\mathrm{CO}$ & 0 & 0 & 0 & 0 & 0 & 0 \\
\hline \multirow[t]{2}{*}{$8 \mathrm{~h}$} & $\mathrm{O}_{3}$ & 0 & 0 & - & - & 78 & 133 \\
\hline & $\mathrm{CO}$ & 0 & 0 & 0 & 0 & 0 & 0 \\
\hline \multirow[t]{3}{*}{$24 \mathrm{~h}$} & $\mathrm{PM}_{10}$ & 8 & 33 & 9 & 35 & 6 & 29 \\
\hline & $\mathrm{PM}_{2.5}$ & 56 & 56 & 52 & 52 & 51 & 51 \\
\hline & $\mathrm{SO}_{2}$ & 0 & 0 & 0 & 0 & 0 & 0 \\
\hline
\end{tabular}

For $\mathrm{O}_{3}$, the 8-h $\mathrm{O}_{3}$ concentration exceeded GAMEP and USEPA standards by 78 and 113 times, respectively, at the work site; $1-\mathrm{h} \mathrm{O}_{3}$ concentrations at the work site exceeded both GAMEP and USEPA standards by two times. At the work site, the lockdown period was better in compliance with the 1-h $\mathrm{O}_{3}$ standard than with the 8-h $\mathrm{O}_{3}$ standard. The 8-h GAMEP standard and USEPA standard were exceeded 39 and 66.5 times, respectively, more often than the 1-h standard during the lockdown period (Table 2). For human health, the 8-h $\mathrm{O}_{3}$ standard provides better protection than the 1-h standard. According to hourly AQI, the lockdown period had less undesirable air $(0.05 \%)$ than the K-post 20 . In contrast, based on the 8h AQI, K-post 20 had less undesirable air (32.56\%) than during the lockdown period. Therefore, exposure times longer than $1 \mathrm{~h}$ were of concern during the lockdown period. As for $\mathrm{PM}_{10}, 24-\mathrm{h}$ exceedances occurred at all stations. These exceedances occurred 8 and 33 times at the residential site, 9 and 35 times at the traffic site, and 6 and 29 times at the work site for the GAMEP and USEPA standards, respectively. Similarly, the 24-h exceedances for $\mathrm{PM}_{2.5}$ occurred at all stations, 56 times at the residential site, 52 times at the traffic site, and 51 times at the work site for the GAMEP and USEPA standards, respectively. Moreover, $\mathrm{PM}_{2.5}$ and $\mathrm{PM}_{10}$ had on average more than $75 \%$ of the measurements indicated as undesired air quality on the index (Table 1) and may have affected the health of the inhabitants of Riyadh City.

\subsection{Insights for improving air quality}


The unintended restriction due to the lockdown could represent an opportunity to better understand potential emission control regulations and strategies and their implications. The concentrations of gaseous criteria air pollutants for the selected weeks were compared to evaluate the extent of these implications. Figure 5 shows the changes in concentrations of gaseous criteria air pollutants $\left(\mathrm{CO}, \mathrm{SO}_{2}\right.$, $\mathrm{NO}_{2}$, and $\mathrm{O}_{3}$ ) in residential, traffic, and work sites during the last week of the pre-lockdown period (the week before lockdown was imposed), the first and last weeks of the lockdown period, and the first week after the lockdown. To estimate whether the effects of the lockdown on pollutant concentrations were significant, an unpaired t-test was used to calculate the pollutant concentrations in the week before the lockdown and the first week of the lockdown (Table 3). In the traffic site (F-station), the median and mean $\mathrm{CO}$ concentrations during the first week of the lockdown period were less than those during the week before the lockdown. The $\mathrm{CO}$ mean and median concentrations of the pre-lockdown period decreased by $15 \%$ and $36 \%$, respectively, in the first week of the lockdown period at the traffic site. However, this decrease was not significant at the 0.01 confidence level (Table 3). Moreover, the interquartile range was wider for the first week of the lockdown period than that for the week before the lockdown, reflecting a higher variability in the observed $\mathrm{CO}$ concentrations during the lockdown period. This higher variability in CO concentration was due to the low traffic during the lockdown hours and high traffic during hours exempted from the lockdown. The $\mathrm{CO}$ concentrations during the first week after the lockdown increased compared with those during the lockdown at the traffic site but did not revert to the levels of the week before imposing the lockdown. This increase was not significant at the 0.01 confidence level (Table 3).

Table 3

Weekly comparisons of the gaseous criteria air pollutants measured at the different sites in Riyadh before and after the lockdown and relative difference between the mean values ( $\downarrow$ denotes a decrease, $\uparrow$ denotes an increase, and * denotes significant change at the 0.01 confidence level according to the T-test).

\begin{tabular}{|c|c|c|c|c|c|c|}
\hline \multicolumn{7}{|l|}{ Pollutant } \\
\hline & \multicolumn{3}{|c|}{ WbLD-1st WLD } & \multicolumn{3}{|c|}{ Last WLD-1st WALD } \\
\hline & \multicolumn{6}{|l|}{ Sites } \\
\hline & Residential & Traffic & Work & Residential & Traffic & Work \\
\hline $\mathrm{CO}$ & $19.2 \downarrow^{*}$ & $15.1 \downarrow$ & - & $28.3 \uparrow^{*}$ & $10.1 \uparrow$ & $18.0 \uparrow^{*}$ \\
\hline $\mathrm{NO}_{2}$ & $25.1 \downarrow^{*}$ & $17.6 \downarrow^{*}$ & - & $10.8 \uparrow$ & $2.9 \downarrow$ & $1.8 \downarrow$ \\
\hline $\mathrm{SO}_{2}$ & $14.0 \downarrow$ & & - & $51.4 \downarrow^{\star}$ & & $60.7 \downarrow^{*}$ \\
\hline \multicolumn{3}{|l|}{$\mathrm{O}_{3}$} & \multicolumn{3}{|l|}{-} & $9.7 \downarrow$ \\
\hline \multicolumn{7}{|c|}{ Observed decrease $(\downarrow) /$ increase $(\uparrow)$ in mean concentrations over a week (\%) } \\
\hline
\end{tabular}

The CO concentrations during the first week after the lockdown increased compared with those during the lockdown at the work site. This distinct upward change was significant at the 0.01 confidence level (Table 3). For the residential site (M-station), the CO concentrations exhibited similar trends of weak 
comparisons as those at the traffic site, except that the $\mathrm{CO}$ concentrations during the first week after the lockdown increased considerably compared with those during the lockdown and exceeded the levels of the week before the lockdown. Both the observed decrease in the $\mathrm{CO}$ concentrations in the first week of the lockdown period and the increase in the $\mathrm{CO}$ concentrations in the first week after the lockdown were significant at the 0.01 confidence level (Table 3 ). This suggested that the air quality benefit resulting from controlling $\mathrm{CO}$ emissions during this lockdown exhibited significant and more distinct changes in $\mathrm{CO}$ concentration levels at the residential and work sites than at the traffic site. Moreover, this change had a longer positive effect on air quality at the work and traffic sites than at the residential site.

$\mathrm{NO}_{2}$ and $\mathrm{SO}_{2}$ are directly emitted into the air from fuel combustion and industrial processes. $\mathrm{NO}_{2}$ concentrations in the traffic site (F-station) decreased by $15 \%$ and $18 \%$ in the median and mean, respectively, during the first week of the lockdown period and exhibited an interquartile range wider for the first week of the lockdown period than that for the week before the lockdown. The decrease in $\mathrm{NO}_{2}$ concentrations during the first week of the lockdown period was significant at the 0.01 confidence level (Table 3). Note that the $\mathrm{NO}_{2}$ concentrations exhibited a considerable increase during the week before the lockdown ended. During the lockdown period, construction activities were exempted from lockdowns. Consequently, the activities of heavy-duty diesel engines (bulldozers, dump and tanker trucks, compactors, cranes, diesel electrical generators, and road rollers) involved in the construction activities in the city of the Riyadh metro network, which has six lines and 85 stations, increased considerably with extended working hours, attaining a 24-h working mode during the last month of the lockdown period. When the lockdown ended, this considerable increase in construction activities returned to the normal precoronavirus operation level. In addition, electricity demand increased; thus, power generation in power plants increased due to progression in warmer conditions as the surface heating increased gradually during the March-May period. Therefore, the $\mathrm{NO}_{2}$ concentrations during the first week after the lockdown decreased only slightly compared with those during the week before the lockdown at the traffic site. This decrease was not significant at the 0.01 confidence level (Table 3). For the work site (K-station), the $\mathrm{NO}_{2}$ concentrations during the first week after the lockdown increased slightly (not significant at the 0.01 confidence level) compared with those during the lockdown. At the residential site (M-station), the $\mathrm{NO}_{2}$ concentrations decreased significantly during the first week after the lockdown was imposed compared with those during the week before the lockdown and an increase after the lockdown compared with those during the week before the lockdown. The 50th percentile of $\mathrm{NO}_{2}$ concentrations during the first week of the lockdown period was less than the lower quartile of the $\mathrm{NO}_{2}$ concentrations during the week before the lockdown. This indicated a significant decrease in the $\mathrm{NO}_{2}$ concentrations of more than two quarters between the pre-lockdown period and first week of the lockdown period in the residential site. This observed distinct decrease in the $\mathrm{NO}_{2}$ concentrations in the first week of the lockdown period was significant at the 0.01 confidence level, whereas the increase in the $\mathrm{NO}_{2}$ concentrations in the first week after the lockdown was not significant at the 0.01 confidence level (Table 3 ). 
For $\mathrm{SO}_{2}$, during the first week after the lockdown, the concentration levels decreased only slightly at the residential site (M-station) compared with those during the week before the lockdown. This trend was understandable considering the exemption of construction activities from the lockdown and the gradual increase in power generation during the March-May period. Both the residential site (M-station) and work site (K-station) exhibited significant decreases in $\mathrm{SO}_{2}$ concentration levels after the lockdown compared with levels observed during the week before the lockdown (Fig. 5 and Table 3).

For $\mathrm{O}_{3}$, comparing the last week of the lockdown period with the first week after the lockdown aided in assessing the persistence of the negative effect of the lockdown on elevated $\mathrm{O}_{3}$ concentration levels. Figure 5 shows that the $\mathrm{O}_{3}$ concentrations during the first week after the lockdown decreased only slightly ( $9.6 \%$ and $4.6 \%$ decrease in the mean and median, respectively) compared with those during the week before (the last week of the lockdown period).

Overall, the unintended experimental conditions provided by the COVID-19 lockdown provided valuable insights for improving air quality. Table 3 suggests that applying comparable control measures over one week will result in a decrease of approximately $19 \%$ and $15 \%$ in the mean CO concentration level at residential and traffic sites, respectively. Similarly, $25 \%$ and $18 \%$ reduction in the $\mathrm{NO}_{2}$ mean concentration level can be achieved at residential and traffic sites, respectively. Moreover, the emission control strategies equivalent to the measures implemented during the lockdown over one week could positively affect air quality in terms of controlling $\mathrm{CO}$ concentration levels that could last for approximately one week at work and traffic sites and a relatively shorter time at residential sites. Similarly, air quality benefits in terms of a decrease in $\mathrm{NO}_{2}$ concentration levels over one week could last for approximately one week at work sites and for a relatively shorter time at traffic and residential sites. However, caution should be applied when reducing $\mathrm{NO}_{2}$ concentration levels because it could result in an increase in $\mathrm{O}_{3}$ concentrations that could last for over a week in hydrocarbon-limited areas, particularly at work sites (Fig. 5). In addition, strict inspection tests and rigorous standards for the emission compliance and working hours of trucks should be strategized because they can counteract any measures to improve air quality in terms of $\mathrm{SO}_{2}$ reduction.

\section{Conclusion}

The results of this study indicate that $\mathrm{CO}$ and $\mathrm{NO}_{2}$ concentrations at the residential and traffic sites were more similar than those at the work site during both the unrestricted and lockdown periods. The concentrations of these two gaseous criteria air pollutants $\left(\mathrm{CO}\right.$ and $\left.\mathrm{NO}_{2}\right)$ declined, while the mean concentration of $\mathrm{O}_{3}$ increased at the work site and $\mathrm{SO}_{2}$ mean concentrations at the residential and work sites increased and decreased, respectively, during the lockdown period. The air quality improved significantly in terms of $\mathrm{CO}$ (reduction of $65 \%$ on average) and $\mathrm{NO}_{2}$ (reduction of $63 \%$ on average) concentrations. However, these improvements were counteracted by increased concentrations of $\mathrm{O}_{3}$ (increase of $5.8 \%$ on average) and $\mathrm{SO}_{2}$ (increase of $27 \%$ on average in residential sites). Air quality index (AQI) results indicated that the contribution to "undesired" air quality by $\mathrm{O}_{3}$ was $35.29 \%$ of the lockdown 
period at the work site. Efforts and efficient strategies to mitigate air pollution are required to ensure good air quality. This paper indicates that emission control strategies equivalent to the measures implemented during the lockdown over one week could positively affect air quality in terms of controlling $\mathrm{CO}$ concentration levels that could last for approximately one week at work and traffic sites and a relatively shorter time at residential sites. Similarly, air quality benefits in terms of a decrease in $\mathrm{NO}_{2}$ concentration levels over one week could last for approximately one week at work sites and a relatively shorter time at traffic and residential sites. In contrast, caution should be applied when reducing $\mathrm{NO}_{2}$ concentration levels because it could result in an increase in $\mathrm{O}_{3}$ concentrations that could last for over a week in hydrocarbon-limited areas.

Our results support decision-making and regulatory authorities in implementing effective regulatory plans to improve air quality. The results of this study could serve as insights for mitigating air pollution levels and might aid policymakers in revising the existing policies and strategies for controlling air pollution and subsequently help in improving air quality for a healthy sustainable environment.

\section{Declarations}

\section{- Ethics approval and consent to participate}

Not applicable.

\section{- Consent for publication}

Not applicable.

\section{- Availability of data and materials}

The datasets used and/or analysed during the current study are available from the corresponding author on reasonable request.

\section{- Consent for publication}

Not applicable.

\section{- Competing interests}

The authors declare that they have no competing interests.

\section{- Authors' contributions}

BA: Conceptualization, Methodology, Writing- Original draft preparation, Supervision;

ZA: Data curation, Writing- Original draft preparation, Visualization, Writing- Reviewing and Editing; and HA: Investigation, Writing- Original draft preparation. 


\section{- Acknowledgments}

The authors are grateful for the Royal Commission for Riyadhand the support and assistance received from a large group of field workers and research assistants at the National Centre for Environmental Technology (NCET), Saudi Arabia. This work was conducted as part of a research project funded by King Abdulaziz City for Science \& Technology (KACST).

\section{References}

1. Alharbi, B.H., Alduwais, A.K., Alhudhodi, A.H., 2017. An analysis of the spatial distribution of 03 and its precursors during summer in the urban atmosphere of Riyadh, Saudi Arabia. Atmos. Pollut. Res. 8, 861-872. https://doi.org/https://doi.org/10.1016/j.apr.2017.02.005

2. Chen, L.-W.A., Chien, L.-C., Li, Y., Lin, G., 2020. Nonuniform impacts of COVID-19 lockdown on air quality over the United States. Sci. Total Environ. 745, 141105.

https://doi.org/https://doi.org/10.1016/j.scitotenv.2020.141105

3. Dantas, G., Siciliano, B., França, B.B., da Silva, C.M., Arbilla, G., 2020. The impact of COVID-19 partial lockdown on the air quality of the city of Rio de Janeiro, Brazil. Sci. Total Environ. 729, 139085. https://doi.org/https://doi.org/10.1016/j.scitotenv.2020.139085

4. Hu, B., Guo, H., Zhou, P., Shi, Z.-L., 2020. Characteristics of SARS-CoV-2 and COVID-19. Nat. Rev. Microbiol. 19, 141-154. https://doi.org/10.1038/s41579-020-00459-7

5. Jacobson, M.Z., 2002. Atmospheric Pollution: History, Science, and Regulation. Cambridge University Press, Cambridge. https://doi.org/DOI: 10.1017/CB09780511802287

6. Johns Hopkins University of Medicine, 2020. COVID-19 dashboard by the Center for Systems Science and Engineering (CSSE) at Johns Hopkins University (JHU) [WWW Document].

7. Kanniah, K.D., Kamarul Zaman, N.A.F., Kaskaoutis, D.G., Latif, M.T., 2020. COVID-19's impact on the atmospheric environment in the Southeast Asia region. Sci. Total Environ. 736, 139658.

https://doi.org/https://doi.org/10.1016/j.scitotenv.2020.139658

8. Kleinman, L.I., Daum, P.H., Lee, Y.-N., Nunnermacker, L.J., Springston, S.R., Weinstein-Lloyd, J., Rudolph, J., 2005. A comparative study of ozone production in five U.S. metropolitan areas. J. Geophys. Res. Atmos. 110. https://doi.org/https://doi.org/10.1029/2004JD005096

9. Li, L., Li, Q., Huang, L., Wang, Q., Zhu, A., Xu, J., Liu, Ziyi, Li, H., Shi, L., Li, R., Azari, M., Wang, Y., Zhang, X., Liu, Zhiqiang, Zhu, Y., Zhang, K., Xue, S., Ooi, M.C.G., Zhang, D., Chan, A., 2020. Air quality changes during the COVID-19 lockdown over the Yangtze River Delta Region: An insight into the impact of human activity pattern changes on air pollution variation. Sci. Total Environ. 732, 139282. https://doi.org/https://doi.org/10.1016/j.scitotenv.2020.139282

10. $\mathrm{MOH}, 2020$. The Saudi Ministry of Health portal [WWW Document]. URL https://www.moh.gov.sa/en/Pages/Default.aspx (accessed 3.30.21).

11. Nie, D., Shen, F., Wang, J., Ma, X., Li, Z., Ge, P., Ou, Y., Jiang, Y., Chen, Meijuan, Chen, Mindong, Wang, T., Ge, X., 2021. Changes of air quality and its associated health and economic burden in 31 
provincial capital cities in China during COVID-19 pandemic. Atmos. Res. 249, 105328.

https://doi.org/https://doi.org/10.1016/j.atmosres.2020.105328

12. Parker, H.A., Hasheminassab, S., Crounse, J.D., Roehl, C.M., Wennberg, P.O., 2020. Impacts of Traffic Reductions Associated With COVID-19 on Southern California Air Quality. Geophys. Res. Lett. 47, e2020GL090164. https://doi.org/https://doi.org/10.1029/2020GL090164

13. Saadat, S., Rawtani, D., Hussain, C.M., 2020. Environmental perspective of COVID-19. Sci. Total Environ. 728, 138870. https://doi.org/https://doi.org/10.1016/j.scitotenv.2020.138870

14. Sharma, S., Zhang, M., Anshika, Gao, J., Zhang, H., Kota, S.H., 2020. Effect of restricted emissions during COVID-19 on air quality in India. Sci. Total Environ. 728, 138878. https://doi.org/https://doi.org/10.1016/j.scitotenv.2020.138878

15. Shi, X., Brasseur, G.P., 2020. The Response in Air Quality to the Reduction of Chinese Economic Activities during the COVID-19 Outbreak. Geophys. Res. Lett. e2020GL088070-e2020GL088070. https://doi.org/10.1029/2020GL088070

16. Sicard, P., Paoletti, E., Agathokleous, E., Araminienè, V., Proietti, C., Coulibaly, F., De Marco, A., 2020. Ozone weekend effect in cities: Deep insights for urban air pollution control. Environ. Res. 191, 110193. https://doi.org/https://doi.org/10.1016/j.envres.2020.110193

17. Siciliano, B., Carvalho, G., da Silva, C.M., Arbilla, G., 2020. The Impact of COVID-19 Partial Lockdown on Primary Pollutant Concentrations in the Atmosphere of Rio de Janeiro and São Paulo Megacities (Brazil). Bull. Environ. Contam. Toxicol. 105, 2-8. https://doi.org/10.1007/s00128-020-02907-9

18. Sillman, S., He, D., 2002. Some theoretical results concerning O3-NOx-VOC chemistry and NOx-VOC indicators. J. Geophys. Res. Atmos. 107, ACH 26-1-ACH 26-15.

https://doi.org/https://doi.org/10.1029/2001JD001123

19. Sillman, S., Logan, J., Wofsy, S., 1990. The Sensitivity of Ozone to Nitrogen Oxides and Hydrocarbons in Regional Ozone Episodes. J. Geophys. Res. 95, 1837-1851.

https://doi.org/10.1029/JD095iD02p01837

20. Steinfeld, J.I., 1998. Atmospheric Chemistry and Physics: From Air Pollution to Climate Change. Environ. Sci. Policy Sustain. Dev. 40, 26. https://doi.org/10.1080/00139157.1999.10544295

21. Tobías, A., Carnerero, C., Reche, C., Massagué, J., Via, M., Minguillón, M.C., Alastuey, A., Querol, X., 2020. Changes in air quality during the lockdown in Barcelona (Spain) one month into the SARS-CoV2 epidemic. Sci. Total Environ. 726, 138540.

https://doi.org/https://doi.org/10.1016/j.scitotenv.2020.138540

22. U.S. Environmental Protection Agency, 1999. Air quality index reporting. Final rule. Fed Reg 40 CFR Part 58:42530-42549. Washington, D.C.

23. WHO, 2020. Novel coronavirus (2019-nCoV) [WWW Document]. URL https://www.euro.who.int/en/health-topics/health-emergencies/novel-coronavirus-2019-ncov_old (accessed 3.30.21).

24. WHO, 2020. WHO Director-General's opening remarks at the media briefing on COVID-19 - 11 March 2020 [WWW Document]. URL https://www.who.int/director-general/speeches/detail/who-director- 
general-s-opening-remarks-at-the-media-briefing-on-covid-19--11-march-2020 (accessed 3.30.21).

25. Wongphatarakul, V., Friedlander, S.K., Pinto, J.P., 1998. A Comparative Study of PM2.5 Ambient Aerosol Chemical Databases. Environ. Sci. Technol. 32, 3926-3934. https://doi.org/10.1021/es9800582

26. Zambrano-Monserrate, M.A., Ruano, M.A., Sanchez-Alcalde, L., 2020. Indirect effects of COVID-19 on the environment. Sci. Total Environ. 728, 138813.

https://doi.org/https://doi.org/10.1016/j.scitotenv.2020.138813

\section{Figures}




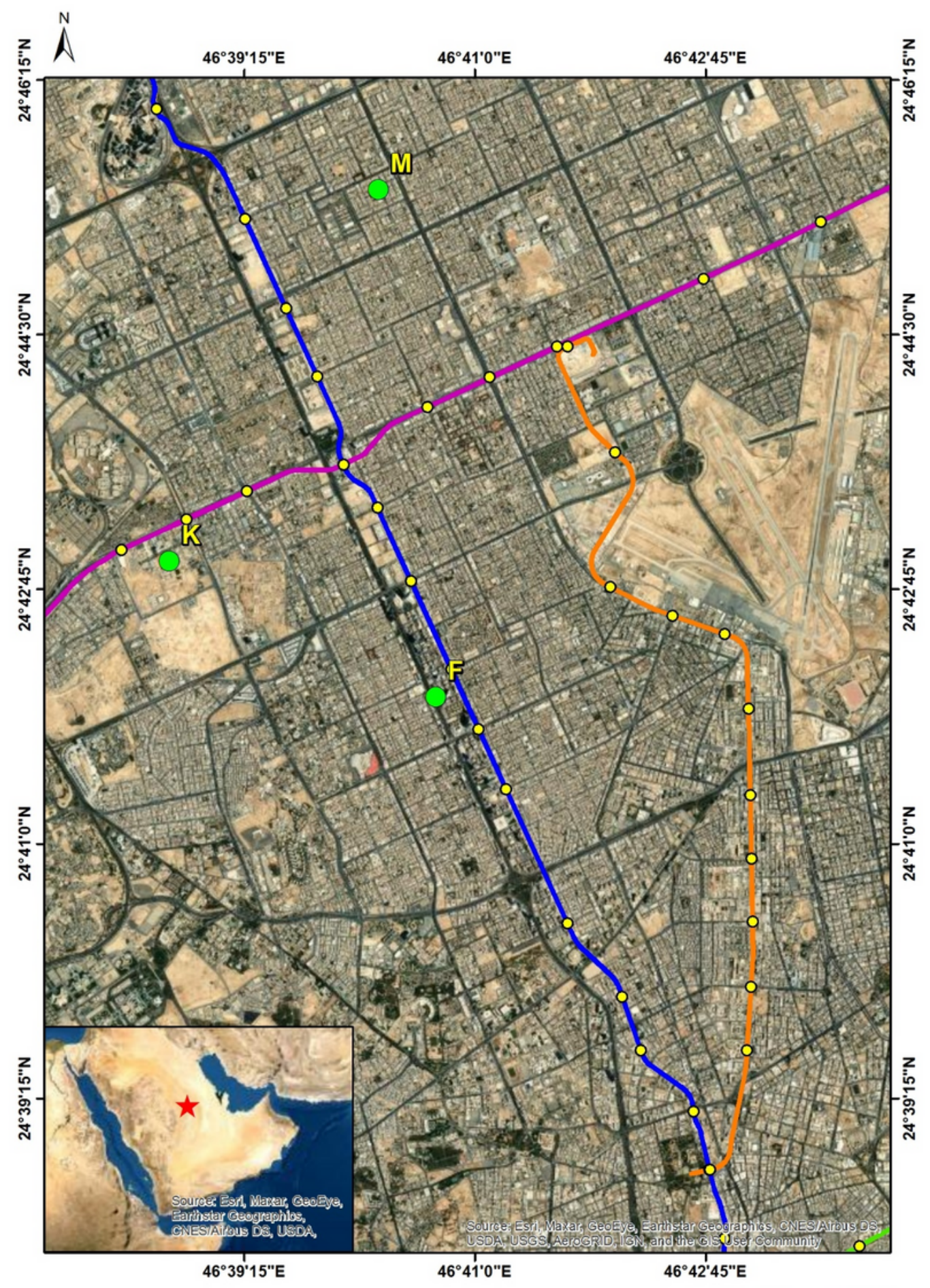

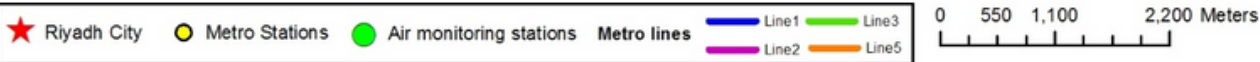

\section{Figure 1}

Locations of air-quality-monitoring stations used in this study and metro stations in Riyadh City. 


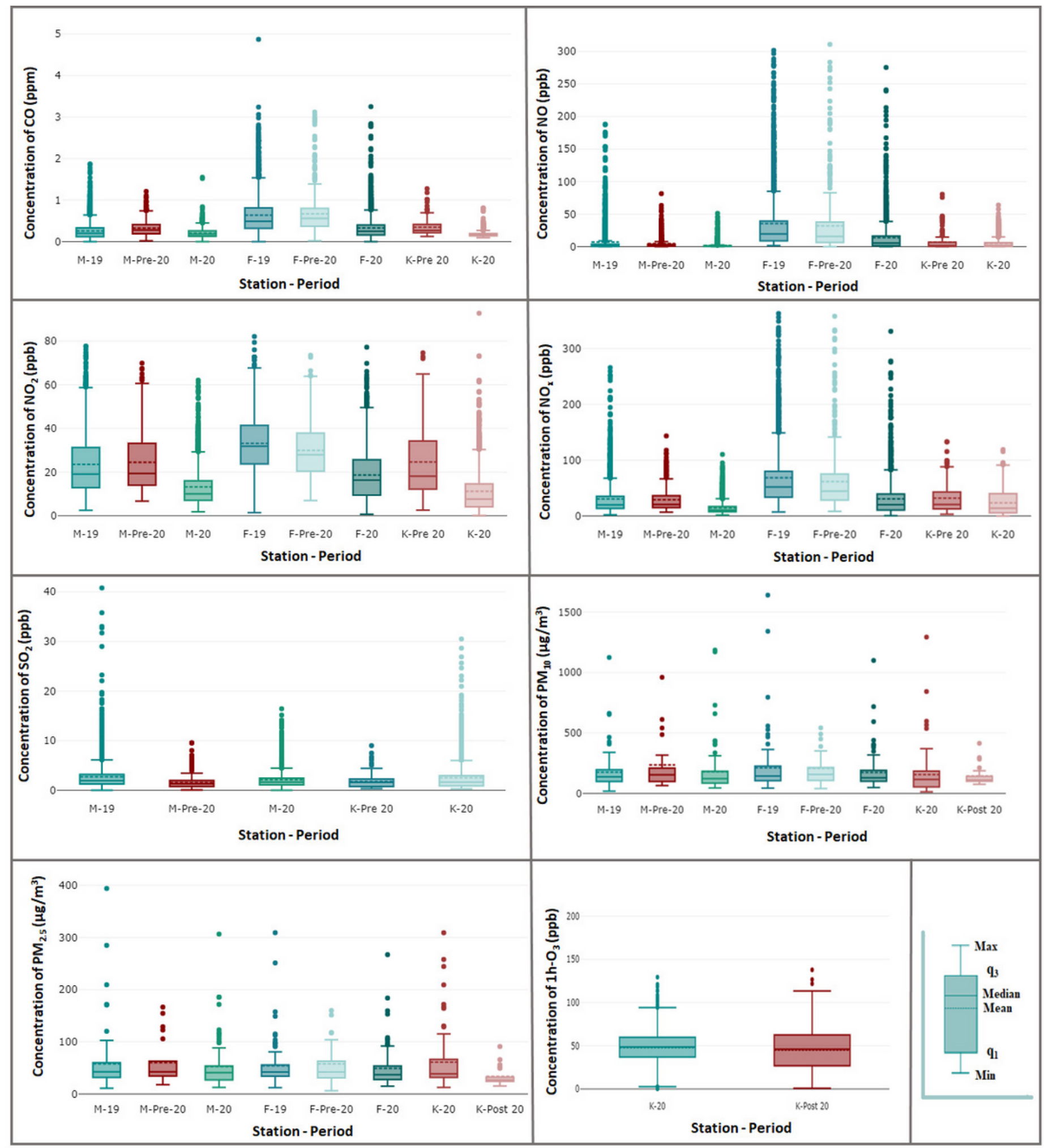

Figure 2

Boxplots of the distributions of 1-h CO, 1-h NO, 1-h NO2, 1-h NOx, 1-h SO2, 1-h 03, 24-h PM2.5, and 24-h PM10 during different periods at three air quality stations $(M, F$, and $K)$. 


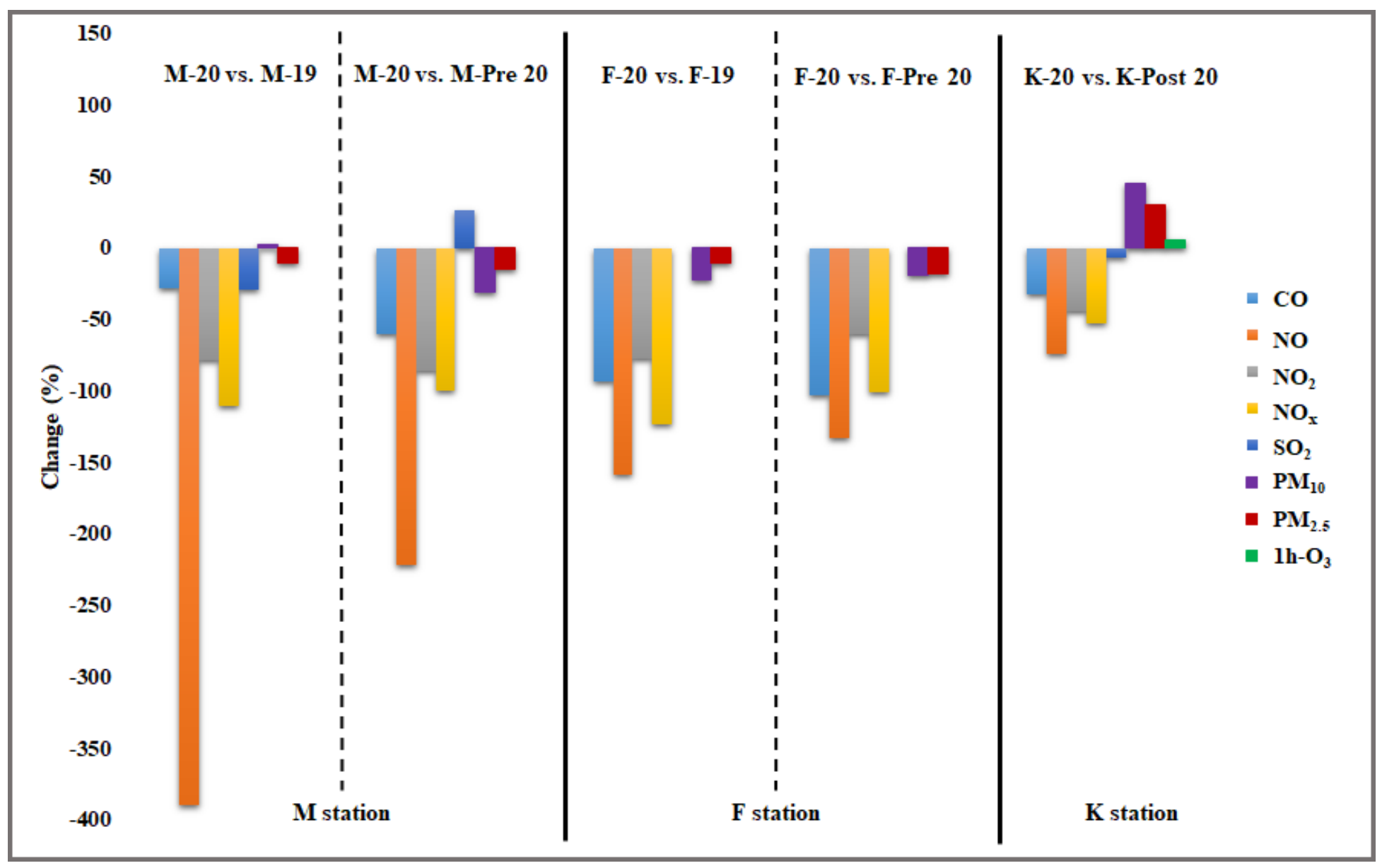

Figure 3

Comparison of air pollutants during the lockdown period for the three stations with the correspondingperiod in 2019 ( $\mathrm{M}$ and $\mathrm{F}$ stations), pre-lockdown period ( $\mathrm{M}$ and $\mathrm{F}$ stations), and post lockdown period (K station). 


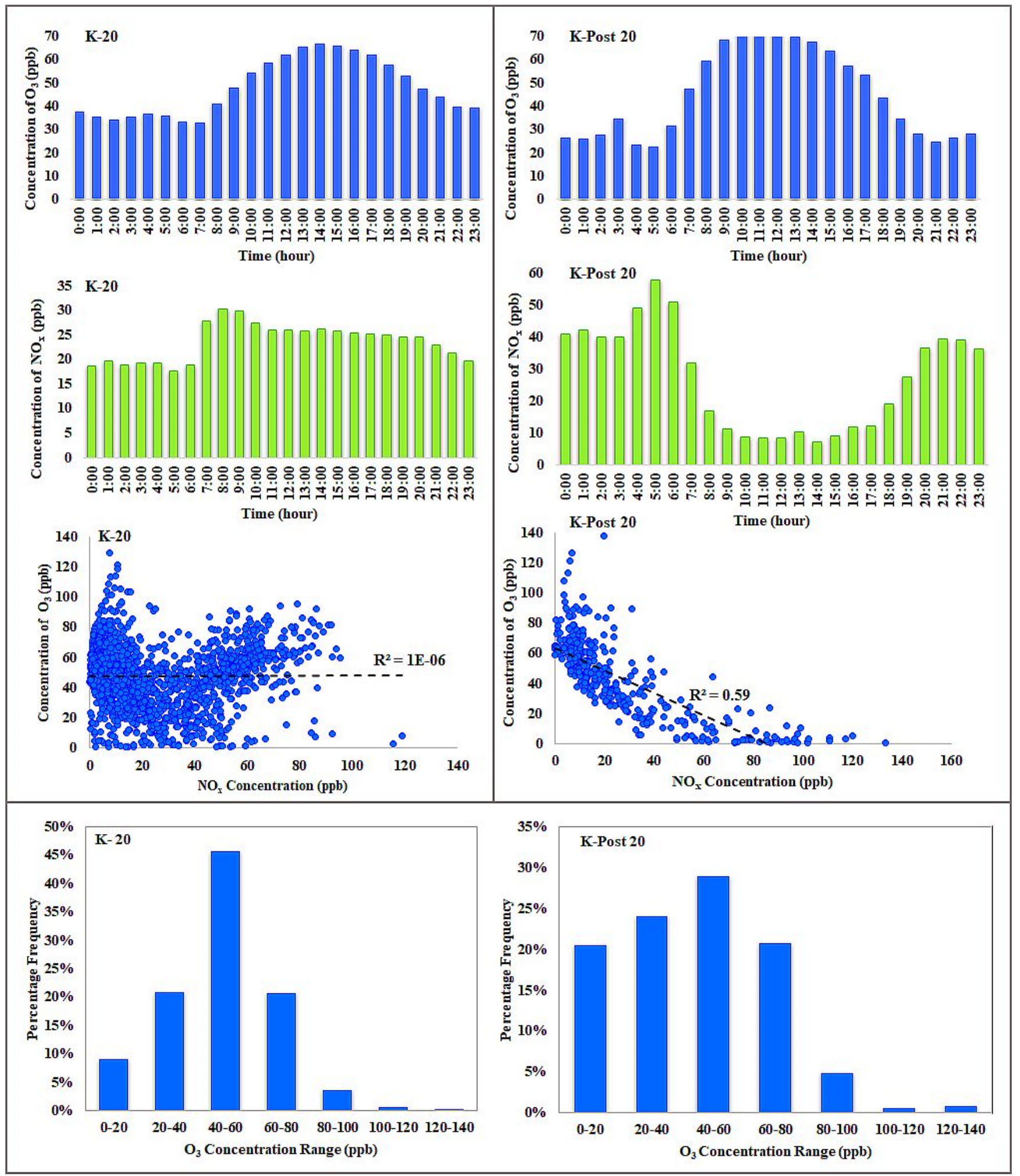

Figure 4

Diurnal distribution of average hourly $\mathrm{O} 3$ ( $a$ and b) and NOx concentrations ( $c$ and d), linear correlations between 03 and NOx (e and f), and frequency distribution of hourly $\mathrm{O3}$ ( $\mathrm{g}$ and $\mathrm{h}$ ) during the lockdown period (K-20) and after the lockdown period (K-Post 20) at the work site (K station). 


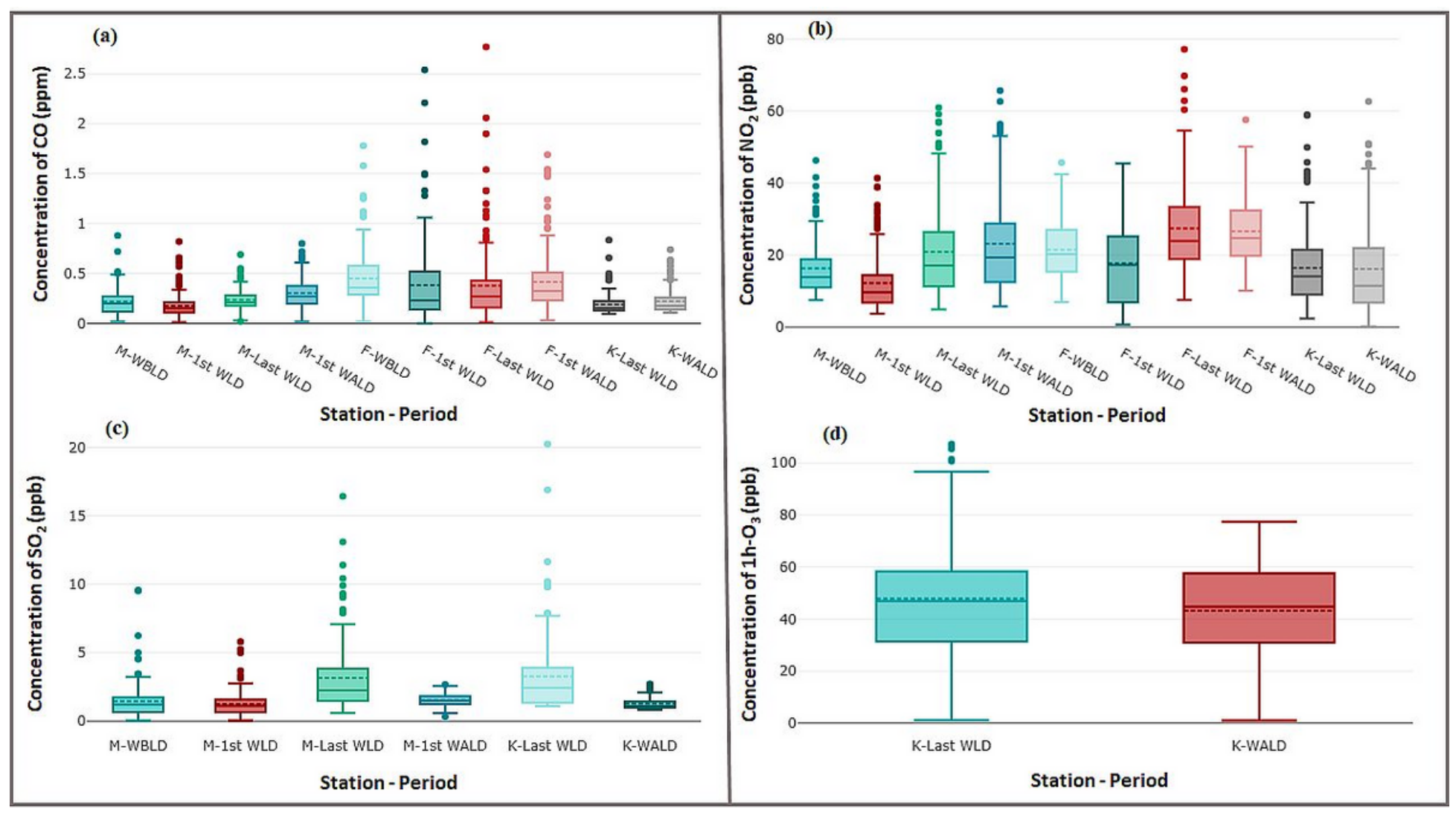

\section{Figure 5}

Concentrations of gaseous criteria air pollutants ( $\mathrm{CO}, \mathrm{SO} 2, \mathrm{NO} 2$, and 03 ) in residential, traffic, and work sites during the last week of pre-lockdown period (the week before imposing the lockdown), the first and last week of lockdown period, and the first week after the lockdown.

\section{Supplementary Files}

This is a list of supplementary files associated with this preprint. Click to download.

- SupplementalMaterial.docx 